KONSTANTIN LiDIN

Irkutsk State Railway University, Russia

\title{
Structure of Information Streams as Social-Psychological Factor of Territories Development
}

\begin{abstract}
The structure of information streams defines the social-psychological atmosphere in a district, a city or a region. The main data carrier are people. Thus, the structure and intensity of flows of people is a defining factor of a social-psychological background for development of territories. A set of historical examples prove it. Will depression, or growth and development reign in the territory? Will the development have a sequenced character, or will criminal tendencies start to prevail? The nature of development of territories depends considerably on how flows of information will be organized.
\end{abstract}

Key words: information flow structure, social-psychology atmosphere, territory development

\section{INTRODUCTION}

Our material world has three aspects. Its tangible aspect reflects the invariability of this world. Its energy aspect reflects its ability to change and move. Having a structure is expressed in the informational aspect of the world. Actually, each aspect is just a mode of seeing this world, like a projection on one of the three planes in drafting. Such perception was invented by people long ago and can be found in the ancient Indian Vedas. Vishnu the Preserver personifies invariability, Shiva the Destroyer embodies changeability, and Brahma the Creator represents structure and order of the world opposed to Chaos.

From the tangible point of view, a human being looks rather modest. In the aspect of the world's invariability, he/she is nothing but a few buckets of salt water and a sackful of calcium phosphate.

In terms of energy, a human being generates only one-tenth of one horsepower. His/her energy efficiency, i.e. power-to-weight ratio, is tens of times less than that of a dove.

In the sense of information, the situation is quite different. Human personality's structure is so complex that its 'informational volume' is hard to imagine. All the knowledge accumulated by mankind, contents of all the libraries and the Internet, movies and pictures, music and voices put together just approximate the informational volume of a single human personality. 


\section{Basic Part}

A human being and the surrounding world are constantly exchanging matter in all its aspects. The informational exchange is of our main interest. The amount of information exchanged between a human being and the environment is as large as the 'informational human being'. A huge, full-flowing river of information is constantly running into the inner world of the personality.

We automatically divide this flow into images. An image is a fragment singled out from the informational flow, like a bucket of water taken from the river. The form of the image, its 'shell' or 'presentation' (according to Roland Barthes), consists of colors and lines, sounds and rhythms, words and movements - everything a human being can perceive with his/her senses, either directly or indirectly. The image content, or the 'water' (Barthes' 'concept'), that assumes the shape of the 'bucket', can change its shape. As water can be poured from one container to another, a scenario can be turned into a movie, a novel - into a ballet, a painting - into its verbal description.

A form can also change its content. It results in a myth. For example, a swastika, one of the oldest solar symbols of the graphical magic. Starting from rock paintings of the Neolithic age, a swastika has been present almost in every culture, every continent and every epoch. However, our western contemporaries can hardly remember the swastika's original meaning. The myth created by national socialists has forced the initial image out of the mass consciousness.

One cannot place any content in any form. It is senseless to pour mud into a cut-glass vase or water from a swimming pool into a glass. There should be certain agreement between the form and the content. In his "The System of Objects”, Jean Baudrillard says: “... a luxury car is in a red described as 'unique'. What 'unique' implies here is not simply that this red can be found nowhere else, but also that it is one with the car's other attributes: the red is not an 'extra'. But no sooner does this colour appear ever so slightly changed on a more 'commercial' car that it becomes the red of thousands of others - a mere detail or accessory feature of cars that are red as an 'extra', because they might just as well be green or black" (Baudrillard 1996: 147). Disagreement and inconsistence between the form and the content give the image an unpleasant tinge of falsehood. If the colour does not 'convey' what the car body lines do, it means that 'one of them is lying'.

The image with all the elements of the form in agreement with each other and with the content is called coherent. It is coherent images that deeply stir sophisticated souls. It is coherent images that trigger emotions of extraordinary intensity. To experience such emotions people buy coherent images, so the market of such images has grown on a global scale. In terms of total sales, the market of the images produced by Hollywood or Bollywood, fiction or theatre, architecture or design is as big as the world oil and metal markets, and its influence on the global economy is definitely greater. Various crises only hasten the growth of this market.

Coherent images become a part and parcel of goods very quickly. An item can hardly be competitive unless it comes with an exciting image. Even a box of drawing pins is decorated 
with a bright label. Cities and countries have to create personal brands to attract tourists, investors and inhabitants. The city that failed to secure a coherent image or create a myth about itself is doomed to depression, being no more attractive even for its own citizens.

Modern urban economy is mostly focused on the tangible and energy aspects of the flows that determine the comfort of city life. The city is treated as an immovable property: the ground for development, buildings on the ground, utilities under the ground, etc. The city energy systems (transport, heating and electricity) are analyzed and developed. However, informational flows, the flows of images running through the urban fabric, are rarely studied by urbanists.

Any flow (including the information flow) can be strong, intensive or weak. At the same time it can be well-ordered or chaotic. According to the characteristics of the information flow, there are four types of the city structure.

Historically, the type of the city based on the minimum intensity of information flows was the first. The people of Mesopotamia and Ancient Egypt worshiped Eternity. Stability and invariability were their highest values. They disliked and even feared any changes. Their desire for stability formed a concentric urban structure with a well-defined center combining administrative, sacral and political functions. This planning of Babylon remained through the times of Sumerians, Akkadians, Hittites and Assyrians. The plans of fortress cities of the early Middle Ages were of the same nature (Figure 1). The idea of eternity was also embodied in the concentric accuracy of the 'ideal cities' naively and fanatically created by the medieval utopianists.

The ideas of an eternal city remained appealing in the modern age. In the early 1930s, the period of stabilization of the Soviet society, the Leningrad reconstruction plans were worked out to relieve the revolutionary ambiance of 'the cradle of the revolution'. The architects L. Ilyin and V. Vitman proposed to relocate the center to the intersection of Moskovsky Avenue and the semicircular main road. The extra monumental House of Soviets was planned to be the focal point of the new downtown area. In 1938-1940 the plan of Leningrad was amended (N. Baranov and A. Naumov with the participation of E. Katonin) so that the development was to become more dense and centralized. Only the war prevented Leningrad from turning into a semblance of Moscow (Bylinkin, Rjabushina 1985).

On the contrary, the desire for maximum increase of information (image-bearing) flows, the pursuit of novelty and changes is expressed in the linear city structure. One of the oldest examples is the city of Akhetaton, the capital built by the Pharaoh-reformer Ekhnaton Amenkhotep IV (Figure 2). From the beginning the city was founded as a multicenter structure: Pharaoh's Palace and the chancery were located in the center, Queen Nefertitti's Palace - in the north; the armory, the police and the parade square - in the western part of the city; and the rich residential quarters for the court nobility - in its southern part. The city extended along the bank of the Nile, the main transport artery of the country. The whole city structure was aimed at easy 'running' of big flows of information. At the middle of the $19^{\text {th }}$ century the similar task was solved by the Parisian prefect baron Haussmann. Purposely, to make more active business life of the city center, he put a network of wide boulevards through a dense historical fabric of the city. 
In the late 1920s, N. A. Ladovsky proposed his famous Moscow development project (Ladovsky Parabola). The plan tried to break one of the rings of the concentric city structure to turn Moscow into a 'dinapolis' (the term was introduced by K. Doxiadis 30 years later). However, this project yielded precedence to the concept of limited development. According to the master plan of 1935, the population was not supposed to exceed five million people, and the number of new enterprises was restricted to municipal services only (Figure 3-4) (Khan-Magomedov 2001).

The desire to achieve maximum order in information flows causes distinct crystal structures, which disregard the terrain, the wind rose, ethnic and property zoning and other natural and social urban realities. After the master plan of Manhattan of 1807 was adopted, the linguist and poet Clement Clarke Moore said about the authors: "These are men who would have cut down the seven hills of Rome" (Gray 2005). However, the example of Manhattan was rather attractive for other cities, which plans are primarily focused on order. Chandigarh and New Delhi, Astana and Example district in Barcelona have a clear structure based on the main values: Order, Law and Reason (Figure 5-6).

The well-ordered structure is opposed by the absence of any structure. The slums and criminal districts, bidonvilles and favelas have one common feature: all these urban phenomena are chaotic and structureless. Accordingly, they are inhabited by venturous people who are inclined to live in chaos and lawlessness and make little account of order.

If one of the four principles of information flow arrangement is applied to the utmost, it suppresses the other three principles and becomes outrageous. When we choose one of the four basic values, we take away the aim and the purpose of life from those people who have different basic values. Whatever we choose, three-quarter of the city population would consider it violence and injustice against them.

In view of the structure of information flows, the role of the city public spaces can be double. The simplest concept is that the quantity and quality of public spaces is subject to a common idea prevailing in the city structure. The squares and parks of the Forbidden City in Beijing are strictly inscribed in its square concentric structure. According to the reconstruction plan of Barcelona worked out by Ildefons Cerda, a strict grid of rectangular modules includes similar public gardens for each module and standardized well-ordered boulevards in diagonal axes. The public spaces of the linear city are 'flowing' and imply energy, people and transport (information in general) moving through them. All this makes the city look uncomfortable and inhuman in the eye of the majority of citizens.

There is also another approach that treats public spaces as a counterbalance to the prevailing tendency. For example, the Central Park in New York with its irregular outlines and intentionally untrimmed plants counterbalances the accurate street grid. The airspace photograph of Zurich shows how the strict structure of residential areas alternates with chaotic spots of greenery and curved lines of river and lake banks. The same is the picture of Vancouver and Melbourne, where the life is officially considered the most comfortable.

According to Mercer's data, for several years Vienna has been the most comfortable city in the world (Mercer's 2012 Quality of Living ranking highlights - Global, 2012). Vienna 
is also highly estimated even by the Anglocentric Economist magazine: in 2011 it was the second city after Melbourne (Liveability Ranking 2012).

The plan of Vienna looks multilayered. Its downtown bordered by Ringstrasse has an old concentric structure of a fortress city. This part of the city is filled with antiquity and traditions. Even not very old buildings (built in the $19-20^{\text {th }}$ centuries) maintain the historical style. Beyond Gürtel the second ring, there are modern districts which deviate from the principle of invariability. On the other bank of the Danube, the linear structure is also obvious. It is composed of the grid of the roads running parallel and perpendicular to the river. Besides, in such districts as Erla, Liesing, Ottakring and Mariabrunn there is a smooth transition between a well-ordered grid of roads and irregular spots of parks and suburban gardens (Figure 7).

Our research showed that various districts of the city of Irkutsk differ both on the level of structure, and emotional atmosphere. The structure of the city center obstructs to traffic of information streams. The practice of "dot building" led to unduly dense building of this district. The tendencies to depressive stances among inhabitants are also characteristic for the city center (Figure 8).

The districts of Irkutsk constructed along wide highways with active movement (Universitetskiy, Academicheskiy, Solnechniy) seems otherwise. Social-psychological inspection showed low level of depressive tendencies.

\section{CONCLUSION}

The structure of information streams defines the social-psychological atmosphere in a district, a city or a region. The main data carrier are people. Thus, the structure and intensity of flows of people is defining factor of a social-psychological background for development of territories. Will depression, or growth and development reign in the territory? Will the development have a sequenced character, or will criminal tendencies start to prevail? Nature of development of territories considerably depends on how flows of people will be organized.

\section{References}

Barthes, R. (1957). Mythologies. Paris: Editions de Seuil.

Baudrillard, J. (translation of Benedict J.). (1996). The System of Objects. London-NY: Verso Books. Bylinkin, P., Rjabushina, M. (eds). (1985). History of Soviet Architecture (1917-1954). Moscow: Stroyizdat. (in Rus.)

Gray, C. (2005). Are Manhattan's Right Angles Wrong? The New York Times, 23 oct.: 68

Khan-Magomedov S.O. (2001). Architecture of Soviet Avant-guarde: Social Problems. Moscow: Stroyizdat. (in Rus.)

Liveability Ranking. Australian Gold (2012). Available at: http://www.economist.com/blogs/gulliver/2012/08/liveability-ranking

Mercer's 2012 Quality of Living ranking highlights - Global (2012). Available at: http://www.mercer. com/qualityofliving 


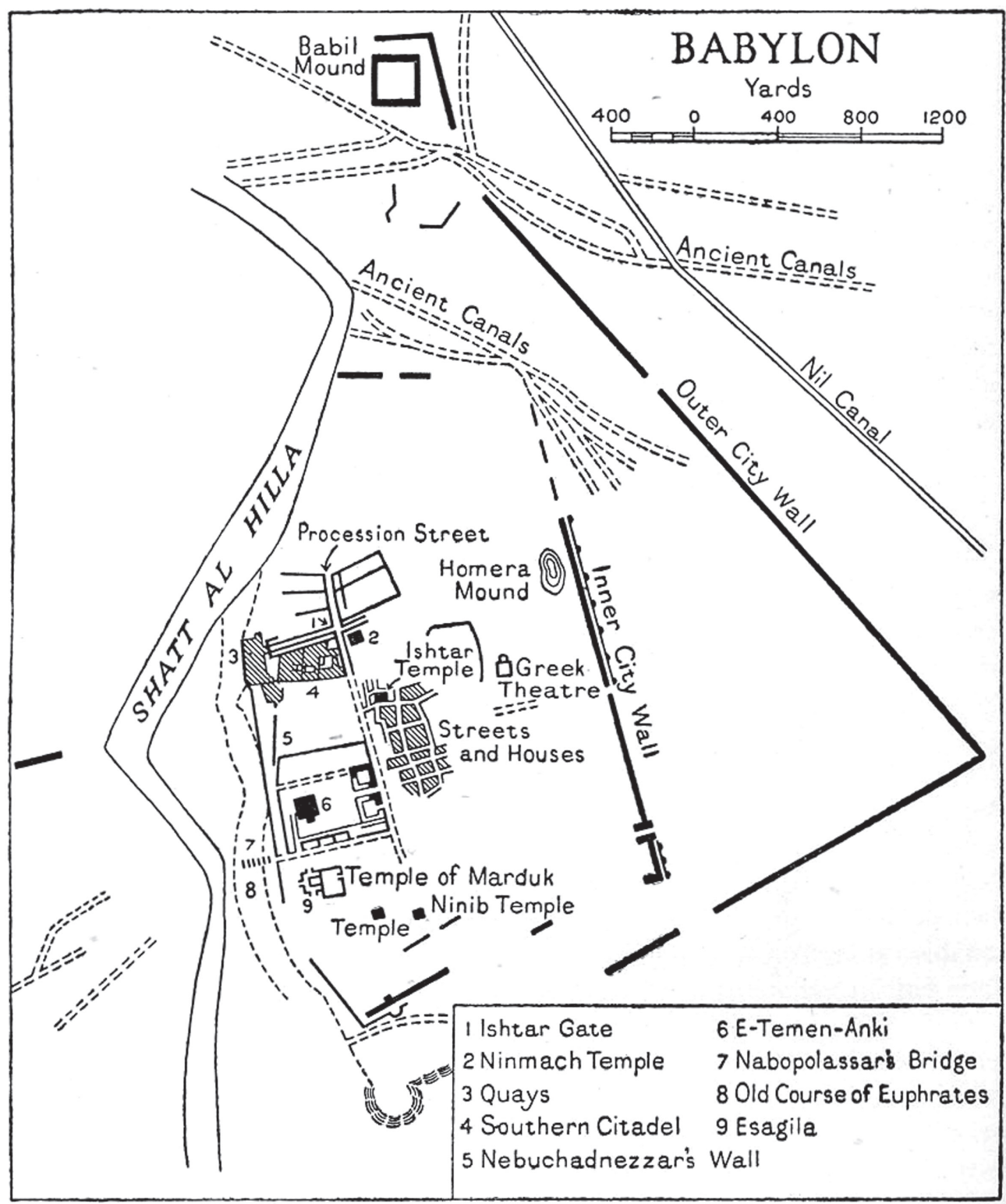

Fig. 1. The plan of Babylon (the Shumerian-Akkadian period). The city structure is strictly centric. The information can only move in a circle or pulsate radially.

The intensity of informational flows is minimal. 


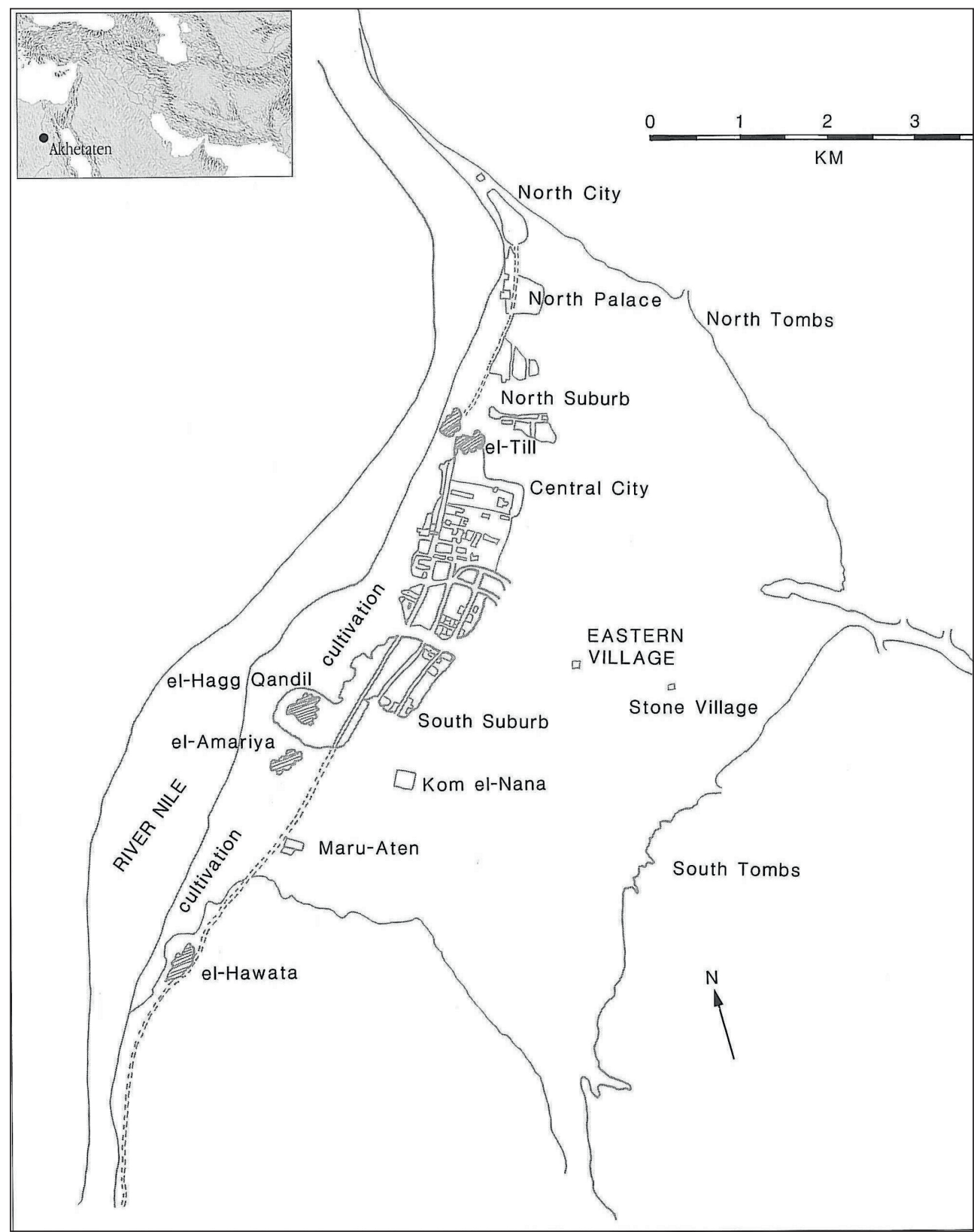

Fig. 2. The plan of Akhetaton is an example of the linear city. Its cut-through structure stimulates informational flows of maximum intensity together with a flow of novelty. 


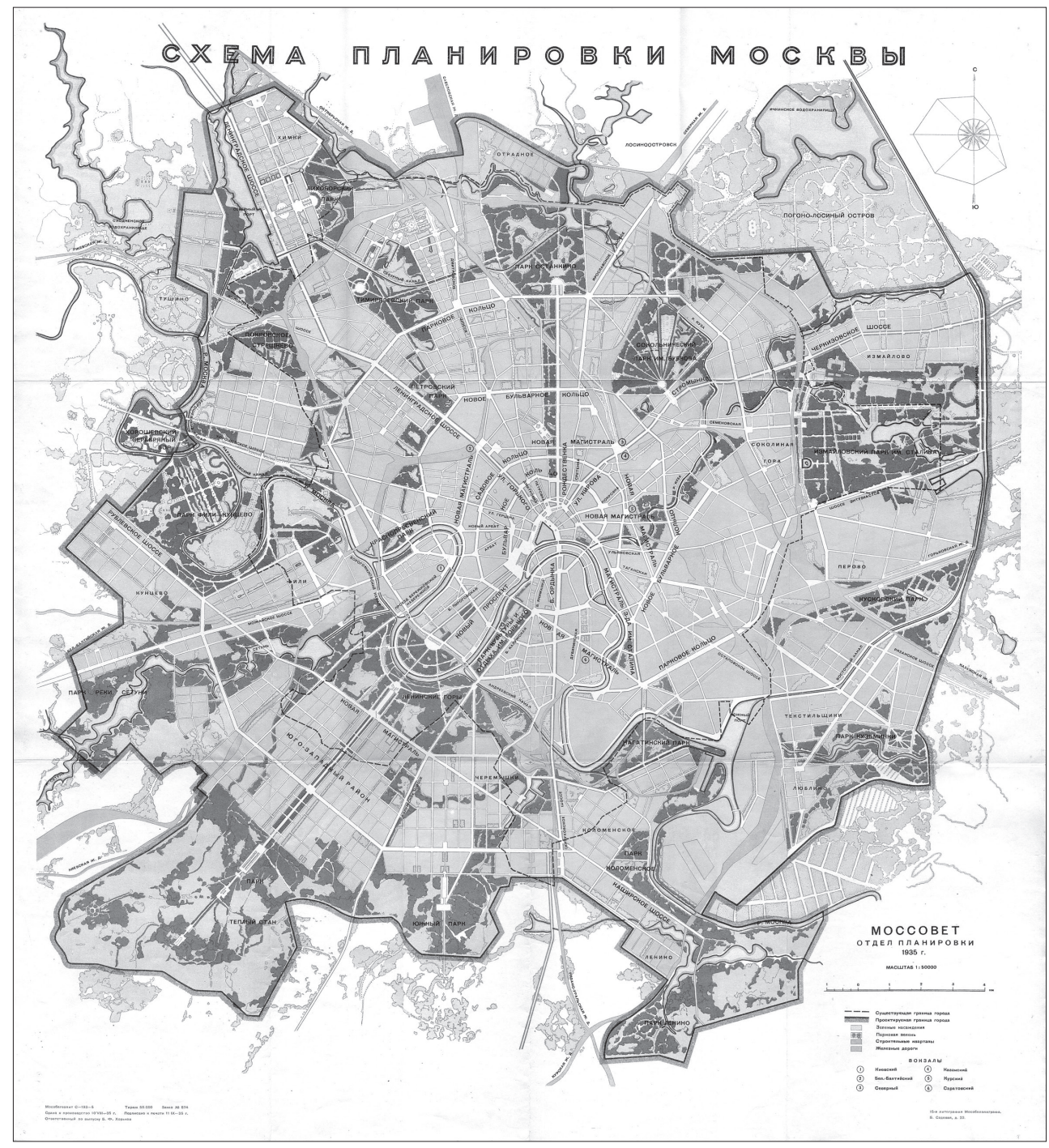

Fig. 3. The reconstruction plan of Moskow, 1935. The radial-concentric structure should slow down information streams and stop city growth. 


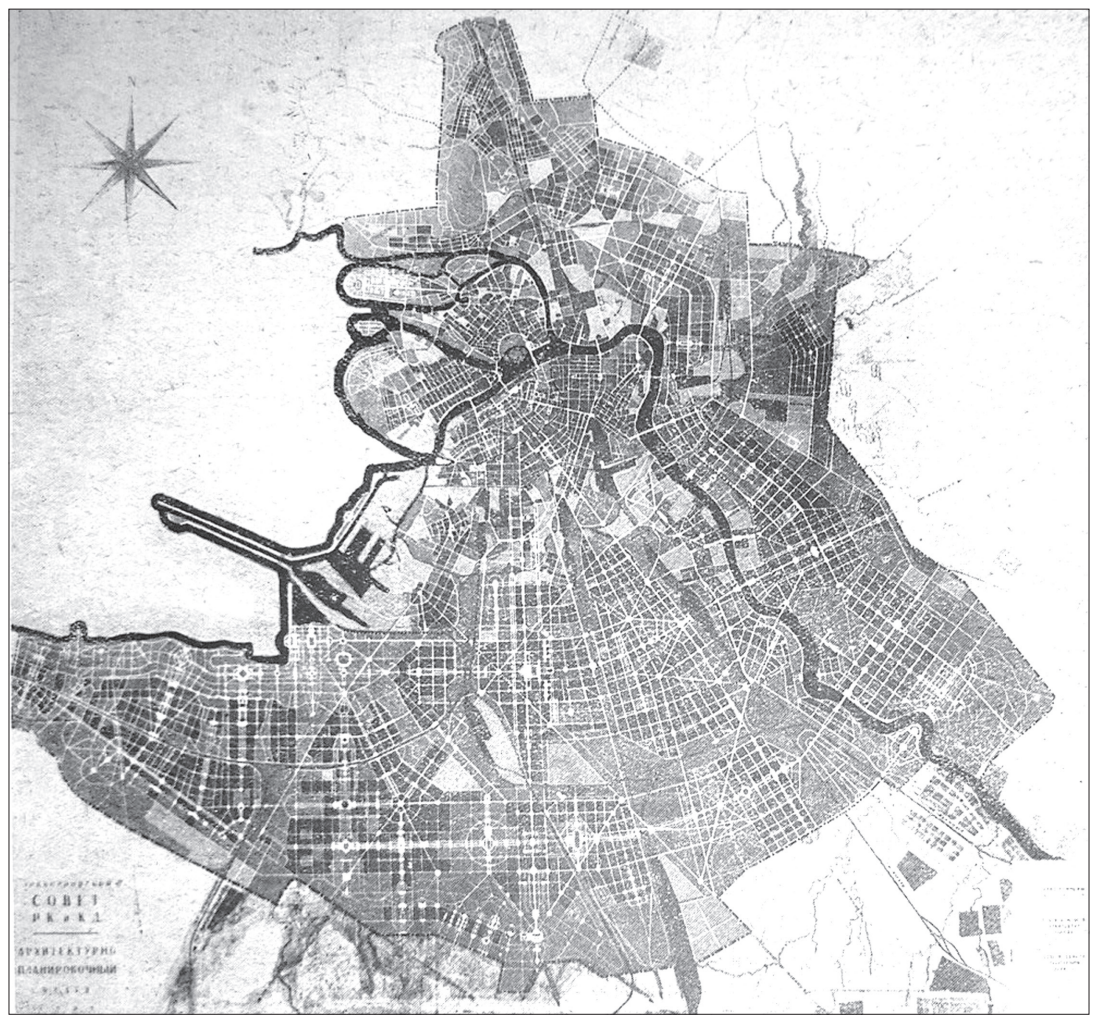

Fig. 4. The reconstruction plan of Leningrad, 1932. The effort to make the layout radial-concentric, like in Moscow, was aimed at calming down the mentality of Leningrad citizens. Similar changes were planned for the plans of Sverdlovsk, Tbilisi, Erevan etc.

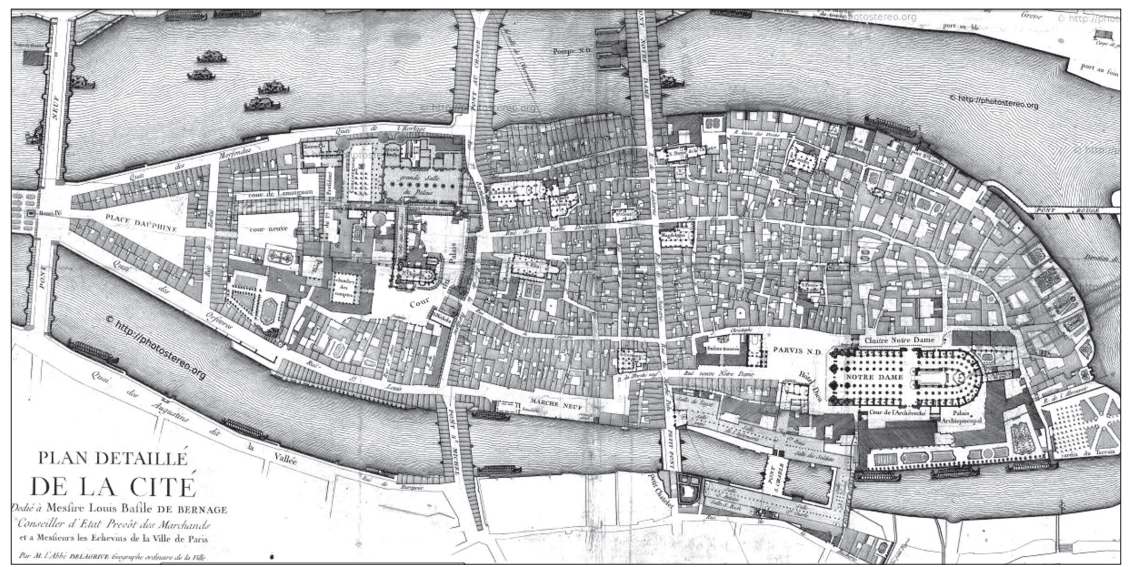

Fig. 5. Plan of business center of Paris - Cite island - at the end of the $18^{\text {th }}$ century. Narrow and curve streets disturb movement of human (information) streams. 


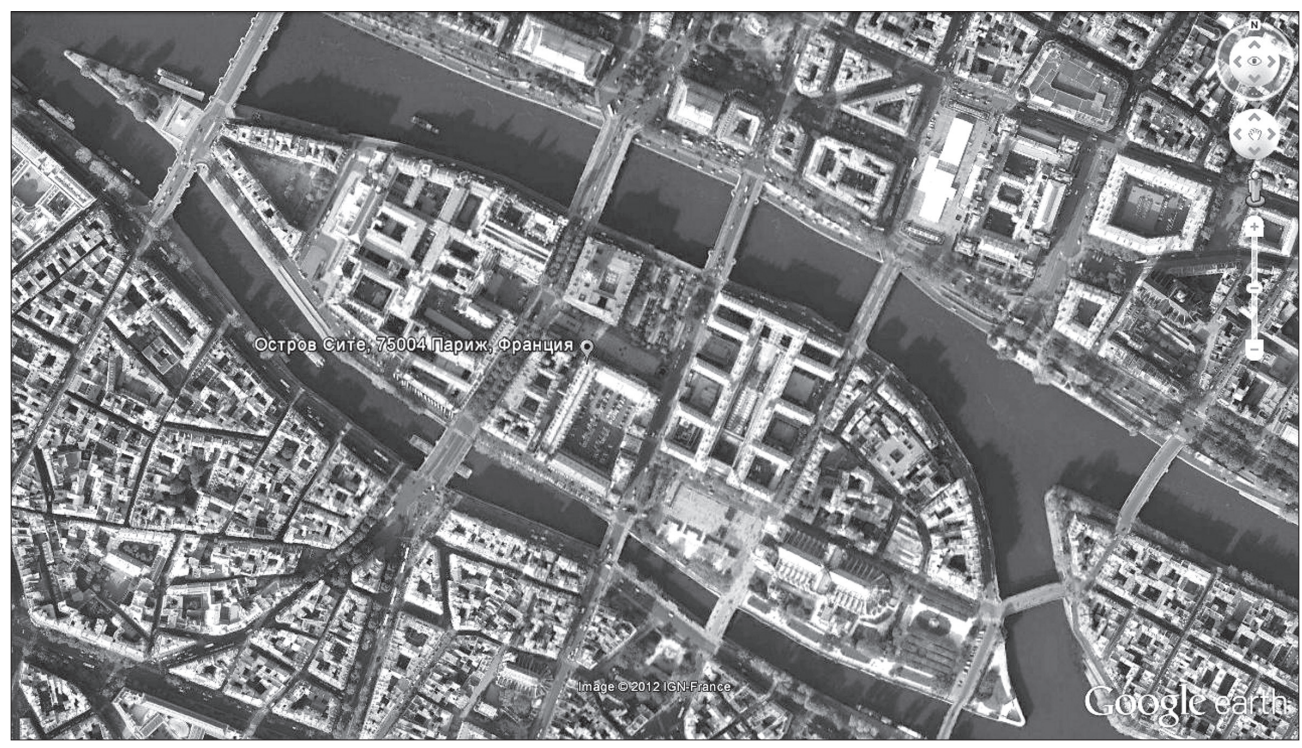

Fig. 6. Modern state of Cite island. Modernization according to the plan of baron Haussmann led to emergence of a number of wide channels of information movement in the direction the South - the North.

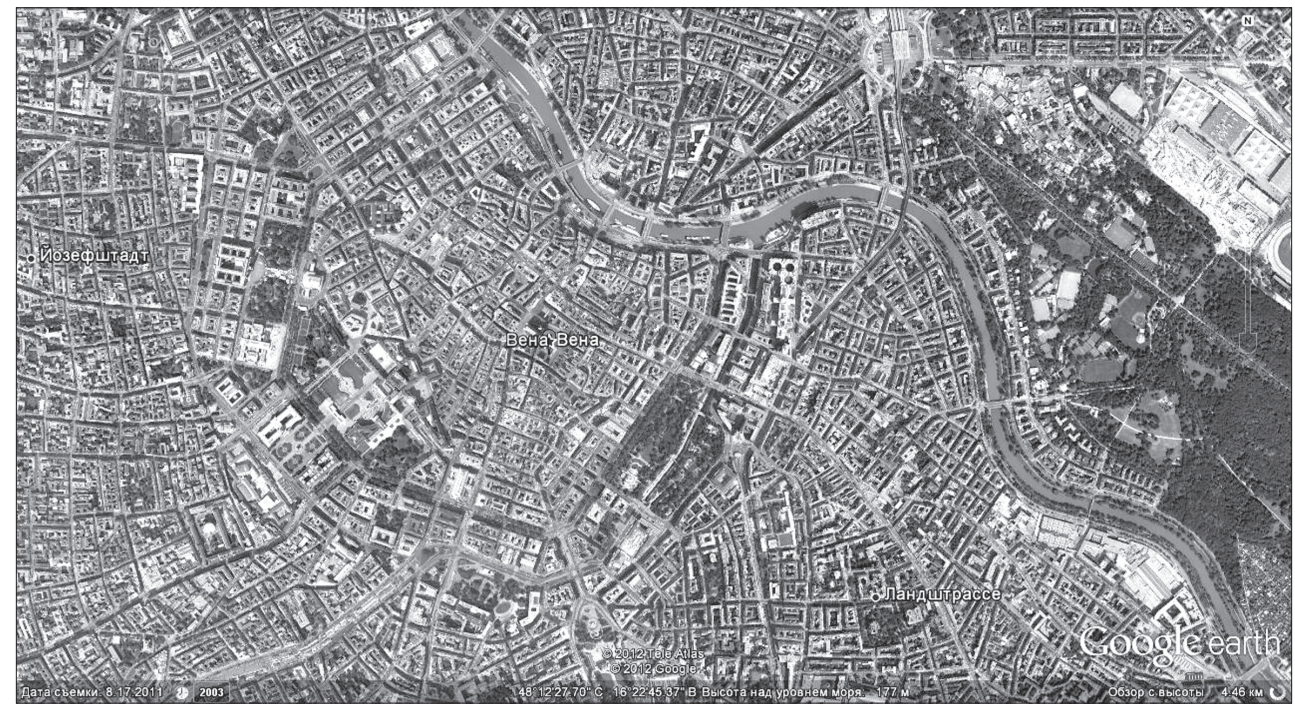

Fig. 7. Center of Vienna, present days. The system of information streams is balanced. The balance between intensity of innovations and conservatism, between orderliness and natural spontaneity is observed. 


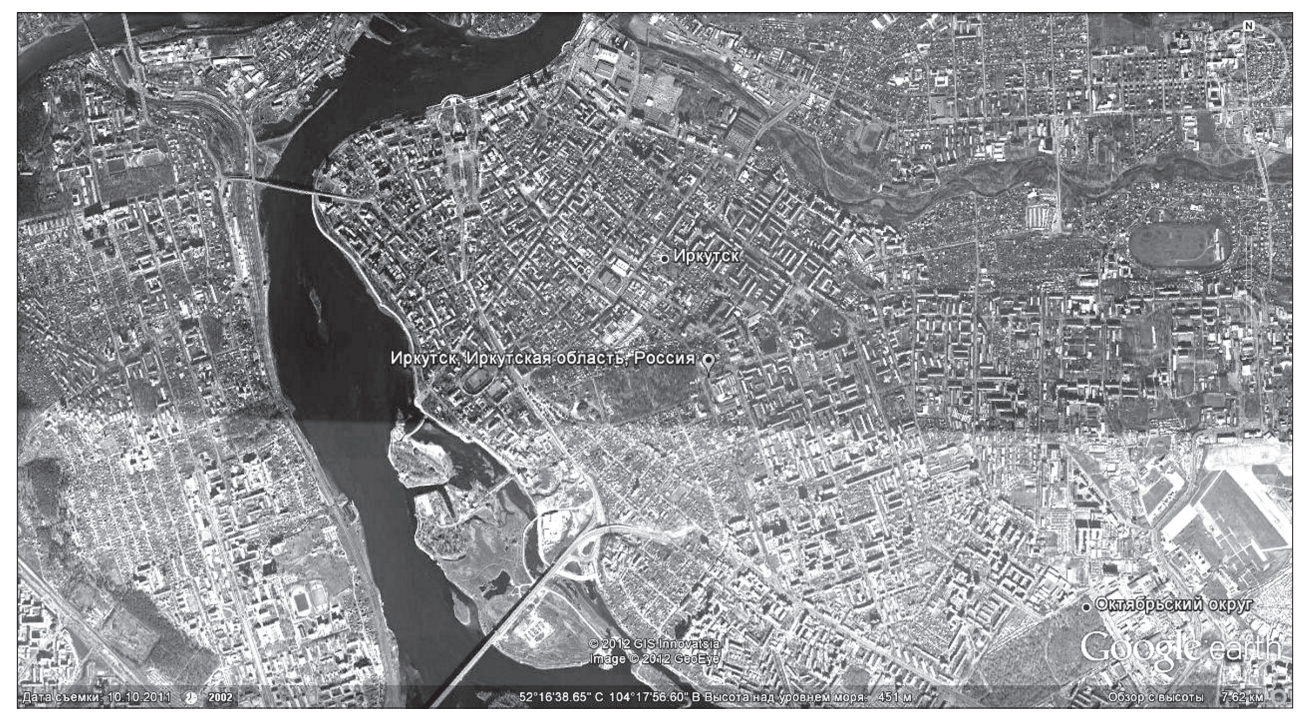

Fig. 8. Center of Irkutsk, present days. The structure of people (information) streams isn't balanced. Channels for information movement are too narrow and chaotic. Tendencies to depression and high level of uneasiness are observed.

Konstantin Lidin, $\mathrm{PhD}$, docent of Irkutsk State Railway University.

Konstantin Lidin (born in 1961), the first diploma and a PhD degree in Technical Chemistry. Twenty years' experience in ore dressing and production of paintwork materials. The second diploma in practical psychology. More than twenty years' experience as psychotherapist (frustration of the emotional sphere, psychosomatic frustration, neurosises). At the same time he worked as the consultant in architectural and design projects. Co-author and participant in more than fifteen projects. The winner of the "Crystal Dedal" (the highest architectural award of Russia) in 2011 for the participation in the "Historical Quarter in the City of Irkutsk" project. Author of four books and seventy articles. Area of scientific interests: psychology of emotions, economy of emotions, perception of territories, cultural geography.

adres/address: Irkutsk State Railway University, 664025 Russia, Irkutsk, Yaroslav Gashek str. 7-38

e-mail: lidink1@hotmail.com 